\title{
Effect of Asparagus Racemosus Willd Root Extract on Ovariectomized Rats
}

\author{
H.R. Chitme*, I.S. Muchandi and S.C. Burli \\ Department of Pharmacology, H. S. K. College of Pharmacy, Bagalkot-Karnataka, 587101, India
}

\begin{abstract}
Osteoporosis is a metabolic bone disease, characterized by increased porosity of the skeleton resulting from reduced bone mass, the associated structural changes predispose the bone to fracture. The drug discovery process in this direction is very attractive, because of non-availability of suitable, safe and effective means for the management of this condition. The objective of the study was to evaluate antiosteoporotic activity of Asparagus racemosus. Ovariectomized rats model was used in this study for evaluation. Effects were evaluated by using biomechanical, bone mineral, serum and urine biochemical parameters. The effect on health status during the treatment was evaluated by regularly checking the overall body weight of the ovariectomized rats. In this study no significant change in body weight was observed. Methanolic and Aqueous extract obtained from Asparagus racemosus root has shown significant $(\mathrm{p}<0.05)$ effect on mineralization, ossification and osteoclastic activity suppression were observed in histopathological examination. Significant $(\mathrm{p}<0.05)$ increase in total ash weight, ash percent and ash calcium content were obtained. Treatments of ovariectomized rats by extract significantly reduced serum alkaline phosphatase activity, serum calcium and also inhibited the ovariectomized induced excessive loss of calcium in urine. Treatment of Aqueous and Methanolic extract of Asparagus racemosus also improved biomechanical parameters including hardness of $4^{\text {th }}$ lumbar vertebra, femoral length and its weight. We conclude from this study that phytosterols and other active constituents present in the root of Asparagus racemosus may effect on estrogen receptor similar to estrogen and produce antiosteoporotics effect. However, activity based fractionation and isolation of active constituents, is required to establish potency, safety and its clinical applicability in osteoporotic condition.
\end{abstract}

Keywords: Osteoporosis, Asparagus racemosusWilld, ovariectomized rats, phytoestrogens.

\section{INTRODUCTION}

Osteoporosis is a disease characterized by low bone mass, micro-architectural deterioration of bone tissue leading to enhanced bone fragility, and a consequent increase in fracture risk, it is a major cause of morbidity and mortality and medical expense worldwide. In India, it is found that $29.9 \%$ of women and $24.3 \%$ of men aged between 20 and 79 year had low bone mass. Furthermore about 50\% women and $36 \%$ of men over 50 years of age were noted to have low bone mass [1]. Osteoporosis affects an estimated 75 million people in the United States, Europe, and Japan combined, including one in three postmenopausal women and majority of the elderly. Osteoporosis cause more than 1,300,000 fractures annually in the United States alone. The disease will be an greater problem in the future, because the world population is aging and the incidence of osteoporotic fractures is increasing in many geographic area [1-2].

The primary osteoporosis include two entities: one related to menopause, estrogen loss and the other to aging. The primary osteoporosis represents two fundamental different conditions. Type I characterized by loss of trabecular bone owing to estrogen deficiency at menopause and type II osteoporosis characterized by loss of cortical and trabecular bone in men and women owing to long-term remodeling,

*Address correspondence to this author at the Oman Medical College, P.O. Box 620, Postal code: 130, Azaiba, Muscat, Sultanate of Oman; Tel: 96899835981, 96824504608-194; Fax: 96824504820;

E-mail: hrchitme@ rediffmail.com inefficiency, dietary inadequate, and activation of the parathyroid axis with age [3].

The goals of management of osteoporosis are to prevent fractures, to decrease the pain when present and to maintain function. Pharmaceutical agents are used to minimize further bone loss [4]. In premenopausal we give calcium, vitamin D supplementation and estrogen as prophylaxis treatments [5]. But hormonal replacement therapy [5], bafilomycin $A_{1}$ [6], androgen replacement therapy [7], parathormone [5], growth hormone [5], Tibolone [8], Phytoestrogens [9], Strontium [10], HMG-CoA Reductase inhibitors [10], and selective estrogen receptor modulators are used in the treatment of osteoporosis [5]. However, most commonly calcium and Vitamin D supplementation, estrogen treatment, bisphosphonate and calcitonin administration are the reparable and widely used for management of osteoporosis [5].

Vitamin D supplementation at higher dose causes hypocalcaemia, hypercalciuria and kidney stone formation [5]. Most commonly estrogen is being used for long term in hormonal replacement therapy, but this causes severe adverse effects like breast cancer, endometrial cancer, vaginal bleeding, blood pressure, thrombo embolism and blood clot [5]. Therapy with bisphosphonates are associated with irritation of esophagus, abdominal or musculoskeletal pain, nausea and heart burn [5], parenteral calcitonin can lead to potential side effects include, nausea, vomiting, diarrhoea, anorexia, facial flashing, tingling, skin rash, edema of the feet and pain at the site of injection [5]. Not only these adverse 
effects and side effects of current pharmacological options of osteoporosis has made to think on use of alternative and complementary medicines but also their inability to restore lost bone mass and bone remodeling [5].

Ayurvedic system of medicines is one of the oldest system of medicine having a history of more than 20 years. Several prototype derived from these herbal medicines are in use for various kind of disease and disorders. It not only gives new molecule but also with newer mechanism of action, hence is called Gold mine. More than 200 drugs have been medicated in ancient texts, but only few of them have been scientifically evaluated, importantly Epimedium brevicornum Maxim [11], Cissus quadrangularis Linn [12] Withania somnifera [13] and Asparagus racemosus which have been known traditionally in Indian system of medicine for the treatment of various metabolic disease and disorders [14]. Since, the present study was carried out to know its applicability in osteoporosis condition. In the present study, extracts of Asparagus racemosus was prepared with methanol and water and used for evaluation of anti-osteoporosis activity, using ovariectomized Wistar rats. This study also involves state of the art animal model to elucidate its probable mechanism of action by following industrial guidelines of FDA, USA for pre-clinical evaluation of anti-osteoporosis drugs [15].

\section{MATERIAL AND METHODS}

\subsection{Materials}

\subsubsection{Instruments}

Klenzieds Laminar air flow, Stat fax ${ }^{\circledR}$ Autoanalyser (2000), Torson's Vacuum desiccators, IME pattern Vernier calipers, Growell Instrument Muffles Furnace, Singla scientific work Pfizer hardness compressor, Remi research centrifuge (C-24), Afcoset Digital balance(E-R-180A)

\subsubsection{Diagnostic Kits}

a) Calcium kits

b) Phosphorus kit

c) Createnine kit

d) Alkaline phosphates kit

(Span diagnostic Ltd. Surat, India) (Span diagnostic Ltd. Surat, India) (Span diagnostic Ltd. Surat, India) (Span diagnostic Ltd. Surat, India)

\subsection{Plant Material}

In the present study, the root of Asparagus racemosus W. was collected in the ayurvedic college Bagalkot, Karnataka India. The plant Asparagus racemosus (W.) (Liliaceae) was authenticated by Prof. V. V. V. Shidlingappanavar, Department of Botany. B.V.V.S, Science college, BagalkotKarnataka India by the studies including organoleptic tests, macroscopic and microscopic observations. The voucher specimen was deposited in the same Institute (BSC /BOT/06/03). Soon after authentication, all roots were dried at room temperature, until they were free from the moisture. Finally the root was subjected to get course powder and then passed through sieve no. 44 to get uniform powder. The sieve powder was stored in air tight, high-density polyethylene container before extraction.

\subsection{Plant Preparation}

The powdered root $(500 \mathrm{~g})$ was subjected to hot continuous extraction (Soxhlet) with methanol. After the residue extraction, solvent was distilled off, and excess solvent was completely removed by using a rotary flash evaporator to get reddish-brown semi solid mass and dried by using Mini Lyotrap freeze dryer at $-20{ }^{\circ} \mathrm{C}$ (yield: $28.17 \%$ ). Water extract was prepared by maceration with mechanical shaking the residue of the methanolic with distilled water for 24 hours. The water extract obtained was dried at $60{ }^{\circ} \mathrm{C}$ on water bath and its percentage yield was calculated $(7.5 \% \mathrm{w} / \mathrm{w})$. The obtained extracts were then evaluated for antiosteoporotic activity after reconstitution in $25 \%$ dimethylesulphoxide (DMSO).

\subsection{Animal Selection}

Forty two (three month old) female Wistar albino rats, weighing between 250 to $300 \mathrm{~g}$, were selected and allowed to acclimatize for a minimum ten days prior to the study. The rats were housed in room maintained of $21 \pm 1^{\circ} \mathrm{c}$, relative humidity $50-55 \%$ and $12 \mathrm{hr}$ light-dark cycle. The rats were caged with one animal in each polypropylene cage and were fed with standard food pellets and water ad libitum throughout the study. The study was conducted in accordance with the CPCSEA guidelines (F.No. 25/27/2005-AWD) for animal experimentation, and was approved by the institutional animal's ethics committee (HSKCP/IAEC. Clear/2004-5, dated $26^{\text {th }}$ Dec 2004). After ten days the rats were divided into seven groups, six rats in each group.

\subsection{Experimental Design}

Ovaiectomy was made by two dorso-lateral incisions, approximately $1 \mathrm{~cm}$ long above the ovaries. With the use of a sharp dissecting scissors, the skin was cut almost together with the dorsal muscles and the peritoneal cavity was thus accessed. After peritoneal cavity was accessed, the ovary was found, surrounded by a variable amount of fat. The surgery was done under anesthesia, using a ketamine $50 \mathrm{mg} / \mathrm{kg}$, intraperitonially. The connection between the fallopian tube and the uterine horn was cut and the ovary moved out. Because of muscle bleeding, its incision required suturing [16]. The rats from all groups were ovariectomized except for rats from group I, which served as sham operated control and treated orally with vehicle $25 \%$ DMSO $(2 \mathrm{ml} / \mathrm{kg})$. The rats from Group 2 received vehicle 25\% DMSO $(2 \mathrm{ml} / \mathrm{kg})$ and served as ovariectomized control. Group 3 was orally administered a standard (estrogen $2 \mathrm{mg} / \mathrm{kg}$ ). Group 4 and 5 were maintained on normal diet, along with oral administration of methanolic extract at 50 and $250 \mathrm{mg} / \mathrm{kg}$, respectively. Group 6 and 7 were subjected to normal diet with oral administration of aqueous extract at 50 and $250 \mathrm{mg} / \mathrm{kg}$ respectively. The extract treatment started on the day of the ovariectomy and continued for 40 days, but the body weight of all animals were recorded at the beginning and weekly intervals throughout the experiment [17]. Twenty-four hour urine samples were collected using separator by placing each group in a metabolic cage during the last week. Urine samples were acidified with $2 \mathrm{ml}$ of $1 \mathrm{M} \mathrm{HCL}$ and centrifuged at $100 \mathrm{~g}$ for $10 \mathrm{~min}$ at $4^{\circ} \mathrm{C}$ to remove contaminating sediments; aliquots were stored at $20^{\circ} \mathrm{C}$ until they were assayed [18].

After 40 days herbal treatment, experimental blood samples from all the Groups were withdrawn by retrorbital, blood samples were allowed to clot at room temperature and the serum was separated by centrifugation at $1000 \mathrm{~g}$ for 20 min. Serum samples were stored at $-20^{\circ} \mathrm{C}$ until analysis [18]. The left and right femur along with tibia was dissected out. 
The left femur were thawed, autoclaved for $15 \mathrm{~min}$ at $110^{\circ} \mathrm{C}$ and divested of soft tissue for the measurement of weight, length, volume and density. The right femur was immediately fixed in $10 \%$ neutral buffered formalin for histopathological examination [17]. During the dissection of bones, the fourth and fifth lumber vertebras were isolated for measuring the mechanical strength and for photography respectively [12].

The lowest and safest dose was selected based on the previous studies [19-25]. The maximum selected dose was five times higher than the regular dose of the extract to know the long term safety and toxicity of extract use [15].

\subsection{Serum Analysis}

The test was carried out using diagnostic reagent kit (Span diagnostic Ltd. Surat, India) for the In vitro determination of calcium. The calcium present in the serum was precipitated with naphtyl hydroxamic acid (calcium reagent). The precipitated was then dissolved in EDTA reagent and calcium from this solution was complexed with color reagent to give a colored complex that was measured colorimetrically [12].

In vitro determination of ALP was carried out by using diagnostic reagent kit (Span diagnostic Ltd). ALP from serum converts phenyl phosphate to inorganic phosphate and phenol at PH 10. Phenol so formed in alkaline medium with 4-aminoantipyrine in presence of oxidizing agent potassiumferricyanide and forms an orange colored complex, which was measured by colorimetric method using an autoanalyzer [12].

\subsection{Urine Analysis}

The calcium, phosphorous and creatinine concentration of urine samples were measured using standard colorimetric method with same kits as earlier used [18].

\subsection{Measurement of Femur Parameter}

a. The femur length, defined as the distance between the greater trochanter and the medial condyle, was meas- ured in the left femurs length using vernier calipers [17].

b. Bone volume and densities were measured by Archimedes's principle. Each bone was placed unstopperd vial filled with deionized water, and the vial was put in a desiccator connected to a vacuum for $90 \mathrm{~min}$. the desiccator was agitated periodically to ensure that all trapped air diffused out of the bone, at which time the bone was removed from the vial, blotted with tissue paper, weighed, and returned to the vial containing deionized water. The bone was reweighed in a boat suspended, but completely immersed, in water previously equilibrated to room temperature, and the density was calculated (grams/volume) [26].

\subsection{Compression $4^{\text {th }}$ Lumbar Vertebra}

During the surgery, the fourth lumbar vertebra was located and then it was isolated. The fresh vertebra was placed in digital Pfizer hardness compressor, until it fractured. The reading was recorded in Newtons [12].

\subsection{Measurement of Ash Weight and Mineral Content of Bone}

After measuring the bone length, the bone was placed in tared fused silica crucibles, and kept in muffles Furnace, dried to a constant temperature at $1000{ }^{\circ} \mathrm{C}$ for 24 hour. Then ash weights were determined and samples were suitably diluted with deionized water to assay for calcium [27].

\subsection{Histopathology of Femur Bone}

The right femur were fixed in $10 \%$ neutral formalin for 12 hour at $4^{\circ} \mathrm{C}$, decalcified in $5 \%$ ethylenediamine tetracetictacid (EDTA) for 7 days, embedded in paraffin and cut into longitudinal section of $5 \mu \mathrm{m}$ thickness. The section were stained with haematoxylin and eosin and tartrate-resistant acid phosphatase (TRAP), a cytochemical marker for osteoclast and finally counter stained with haematoxylin. The number of positively stained osteoclast in the section of the median portion of the whole femora was enumerated for the all groups [17].

Table 1. Effect of Asparagus racemosus Extract on Body Weight (gms) in Ovariectomized Rats

\begin{tabular}{|l|l|l|l|l|l|}
\hline Treatment & Initial Body Weight & Week 1 & Week 2 & Week 3 & Week 4 \\
\hline \hline Normal Rats + DMSO & $220.83 \pm 13.57$ & $220.83 \pm 13.57$ & $226.7 \pm 13.60$ & $223.3 \pm 12.36$ & $233.0 \pm 14.65$ \\
\hline Ovariectomized Rats + DMSO & $204.2 \pm 16.35$ & $204.2 \pm 16.35$ & $195.3 \pm 15.76$ & $199.7 \pm 16.14$ & $202.7 \pm 16.18$ \\
\hline $\begin{array}{l}\text { Ovariectomized Rats + Estrogen }(2 \\
\mathrm{mg} / \mathrm{kg})\end{array}$ & $216.7 \pm 16.67$ & $216.7 \pm 16.67$ & $211.3 \pm 15.38$ & $216.0 \pm 15.94$ & $217.8 \pm 16.43$ \\
\hline $\begin{array}{l}\text { Ovariectomized Rats + Aqueous } \\
\text { Extract (50 m/kg) }\end{array}$ & $216.7 \pm 12.36$ & $216.7 \pm 12.36$ & $200.8 \pm 13.37$ & $207.7 \pm 13.66$ & $212.8 \pm 12.12$ \\
\hline $\begin{array}{l}\text { Ovariectomized Rats + Aqueous } \\
\text { Extract (250 mg/kg) }\end{array}$ & $204.2 \pm 11.93$ & $204.2 \pm 11.93$ & $197.3 \pm 13.83$ & $198.8 \pm 13.40$ & $201.0 \pm 12.86$ \\
\hline $\begin{array}{l}\text { Ovariectomized Rats + Methanolic } \\
\text { Extract (50 mg/kg) }\end{array}$ & $208.3 \pm 13.94$ & $208.3 \pm 13.94$ & $197.8 \pm 14.53$ & $201.5 \pm 14.42$ & $205.2 \pm 13.87$ \\
\hline $\begin{array}{l}\text { Ovariectomized Rats + Methanolic } \\
\text { Extract (250 mg/kg) }\end{array}$ & $208.3 \pm 10.54$ & $208.3 \pm 10.54$ & $200.2 \pm 10.61$ & $203.2 \pm 10.67$ & $206.3 \pm 10.80$ \\
\hline
\end{tabular}

Effect of Asparagus racemosus extract on body weight in ovariectomized rats was calculated from first day of study and every week regularly. The body weight of each animal was recorded one hour prior to administration of drug extract on recording day. The results are depicted as mean \pm S.E.M. and analysed by student ' $t$ ' test for coming to conclusion. 


\subsection{Statistical Analysis}

All the data collected in the present study are expressed as Mean \pm SE and were analysed by student ' $t$ ' test for coming to conclusion.

\section{RESULTS}

\subsection{Effect of Asparagus racemosus Extract on Ovariec- tomized Induced Rats Body Weight Changes}

Table 1, show no significant changes in body weight in ovariectomized rats comparable to sham operated control. It was also noticed that no significant changes in body weight in animals treated with Asparagus racemosus Methanolic (50 and $250 \mathrm{mg} / \mathrm{kg} \mathrm{p.o)}$ and Aqueous (50 and $250 \mathrm{mg} / \mathrm{kg}$ p.o) extract compared to ovariectomized rats.

\subsection{Effect of Asparagus racemosusu Extract on Ovariec- tomized Rats Changes in Biomechanical Properties of Bone}

As shown in Table 2, the femoral weight, volume, density and hardness of $4^{\text {th }}$ lumbar vertebra were not significantly changed in ovariectomized rats as compared to shamoperated animals. In groups treated with Methanolic (50 and $250 \mathrm{mg} / \mathrm{kg} \mathrm{PO}$ ) and Aqueous extract of Asparagus racemosus no significant changes in femoral volume, density, and also $4^{\text {th }}$ lumbar vertebral hardness when compared with those in ovariectomized control. However, femoral length of ovariectomized rats was significantly decreased $(\mathrm{p}<0.05)$ as compared to normal control rats. Treatments of ovariectomized rats with Methanolic and Aqueous extract significantly inhibited ovariectomized effects on femoral length, volume, density and hardness of $4^{\text {th }}$ lumbar bone was seen, but it significantly increased $(\mathrm{p}<0.01)$ femoral weight when compared to sham-operated rats. Asparagus racemosus aqueous extract has no significant effect on change in femoral weight, where as Methanolic extract shown significant $(p<0.05)$ and $(p<0.01)$ dose dependent increase in femoral weight when compared to control ovariectomized rats. The changes in femoral weight may be due to different extracts but not the doses as the gain in weight observed in methanolic extract treated groups irrespective of doses selected. No significant change in femoral density and $4^{\text {th }}$ lumbar hardness was observed in any treated group of animals when compared to control group.

\subsection{Effect of Asparagus racemosus Extract on Biochemi- cal Marker in Ovariectomized Rats}

Significant differences were found in serum level of alkaline phosphatase in ovariectomized rats to normal and treated ovariectomized rats. In below mentioned Table 3, significance $6.01 \pm 0.23(\mathrm{p}<0.01)$ decreased in serum calcium ion level was found. Treatment of ovariectomized rats with Estrogen and Aqueous extract of Asparagus racemosus not show any significant change in serum level, however, Methanolic extract significantly $(\mathrm{p}<0.05)$ increased serum calcium level when compared to ovariectomized rats. Significantly $(\mathrm{p}<0.05)$ serum phosphorus level was decreased in ovariectomized rats $4.5 \pm 0.45$, but no significant change in serum phosphorous level was observed with estrogen, aqueous extract an methanolic extract treatment. Methanolic extract of Asparagus racemosus significantly $(\mathrm{p}<0.05)$ reduced renal creatinine clearance when compared to ovariectomized rats, however estrogen and methanolic extract has no significant influence in this process. Loss of calcium ion in urine was significantly $(\mathrm{p}<0.05)$ increased when rats were treated with estrogen and methanolic extract at low dose $(50 \mathrm{mg} / \mathrm{kg})$ when compared to ovariectomized rats. Urine phosphorous level was significantly decreased $(p<0.001)$ to 1.5 in ovariectomized rats when compared to sham-operated rats.

Table 2. Effect of Asparagus racemosus Extract on Femoral Length, Weight, Volume, Density and $4^{\text {th }}$ Lumbar Hardness in Ovariectomized Rats

\begin{tabular}{|l|l|l|l|l|l|}
\hline Treatment & Length $(\mathbf{c m})$ & Weight $(\mathbf{g})$ & Volume $(\mathbf{m l})$ & Density $(\mathbf{g} / \mathbf{m l})$ & $\begin{array}{l}4^{\text {th }} \mathbf{L u m b a r ~ H a r d n e s s ~} \\
(\mathbf{k g} / \mathbf{m}) \mathbf{~ N}\end{array}$ \\
\hline \hline Normal Rats + DMSO & $3.36 \pm 0.06$ & $0.65 \pm .02$ & $0.52 \pm$ & $1.24 \pm 0.52$ & $214.6 \pm 28.64$ \\
\hline Ovariectomized Rats + DMSO & $3.07 \pm 0.07^{*}$ & $0.48 \pm 0.01$ & $0.3 \pm 0.03$ & $1.47 \pm 0.29$ & $176.2 \pm 26.68$ \\
\hline $\begin{array}{l}\text { Ovariectomized Rats + Estrogen }(2 \\
\mathrm{mg} / \mathrm{kg})\end{array}$ & $3.43 \pm 0.05$ & $0.66 \pm 0.03^{* *}$ & $0.44 \pm 0.04$ & $1.54 \pm 0.16$ & $210.1 \pm 29.31$ \\
\hline $\begin{array}{l}\text { Ovariectomized Rats + Aqueous Extract } \\
(50 \mathrm{mg} / \mathrm{kg})\end{array}$ & $3.32 \pm 0.03^{*}$ & $0.5 \pm 0.01$ & $0.34 \pm 0.01$ & $1.48 \pm 0.04$ & $323.6 \pm 29.3$ \\
\hline $\begin{array}{l}\text { Ovariectomized Rats + Aqueous Extract } \\
(250 \mathrm{mg} / \mathrm{kg})\end{array}$ & $3.49 \pm 0.02^{* *}$ & $0.5 \pm 0.02$ & $0.38 \pm 0.02$ & $1.34 \pm 0.08$ & $184.5 \pm 21.45$ \\
\hline $\begin{array}{l}\text { Ovariectomized Rats + Methanolic Extract } \\
(50 \mathrm{mg} / \mathrm{kg})\end{array}$ & $3.44 \pm 0.02^{* *}$ & $0.6 \pm 0.03 *$ & $0.38 \pm 0.03$ & $1.61 \pm 0.08$ & $227.3 \pm 25.85$ \\
\hline $\begin{array}{l}\text { Ovariectomized Rats + Methanolic Extract } \\
(250 \mathrm{mg} / \mathrm{kg})\end{array}$ & $3.44 \pm 0.04^{*}$ & $0.6 \pm 0.01^{* *}$ & $0.36 \pm 0.02$ & $1.67 \pm 0.06$ & $182.6 \pm 26.93$ \\
\hline
\end{tabular}

The effect of Asparagus racemosus extract on bone mechanical parameters were recorded on $40^{\text {th }}$ day of study. On $40^{\text {th }}$ day animals were anesthetized by over dose of ether, left and right femur along with $4^{\text {th }}$ and $5^{\text {th }}$ lumbar vertebra were separated. Left femur was selected for bone mechanical parameter and right femur was for histopathological studies. The 4 th lumbar vertebra was used for hardness test and $5^{\text {th }}$ lumbar vertebra for morphological study by photography. Femur length was measured by using a varnier calipers, weight was measured by using Afcoset digital balance, volume was measured by following Archimedes's principle and density was calculated based on weight and volume. Lumbar hardness was recorded by using digital compressor and expressed in Newton units. Results were analysed by student ' $t$ ' test and are expressed as Mean \pm SE. $\mathrm{p}$ value less than 0.05 was considered as significant. ${ }^{*} \mathrm{p}<0.05, * * \mathrm{p}<0.01$. 
Table 3. Effect of Asparagus racemosus Extract on Serum and Urinary Biochemical Markers in Ovariectomized Rats

\begin{tabular}{|c|c|c|c|c|c|c|}
\hline Treatment & \multicolumn{3}{|l|}{ Serum } & \multicolumn{3}{|l|}{ Urine } \\
\hline Normal Rats + DMSO & $229.4 \pm 40.95$ & $8.35 \pm 0.36$ & $11.17 \pm 2.41$ & 12.7 & 1.6 & 4.2 \\
\hline Ovariectomized Rats + DMSO & $283.7 \pm 32.88$ & $6.01 \pm 0.23 * *$ & $4.50 \pm 0.45 *$ & 6.38 & $11^{*}$ & $1.5 * * *$ \\
\hline $\begin{array}{l}\text { Ovariectomized Rats + Aqueous } \\
\text { Extract }(50 \mathrm{mg} / \mathrm{kg})\end{array}$ & $181.4 \pm 33.33^{*}$ & $6.5 \pm 0.28$ & $6.45 \pm 0.95$ & 1.3 & 7.2 & 2.3 \\
\hline $\begin{array}{l}\text { Ovariectomized Rats + Aqueous } \\
\text { Extract }(250 \mathrm{mg} / \mathrm{kg})\end{array}$ & $157.8 \pm 17.56 * *$ & $6.08 \pm 0.26$ & $6.48 \pm 074$ & 2.0 & 8.3 & 0.3 \\
\hline $\begin{array}{l}\text { Ovariectomized Rats }+ \\
\text { Methanolic Extract }(250 \mathrm{mg} / \mathrm{kg})\end{array}$ & $229.2 \pm 22.26^{*}$ & $7.28 \pm 0.36 *$ & $4.21 \pm 0.29$ & $0.2^{*}$ & 7.5 & 3.1 \\
\hline
\end{tabular}

Effect of Asparagus racemosus extract on ovariectomized rats was studied by serum and urine biochemical analysis. Biochemical parameters were estimated by using Span diagnostic kits purchased from local market. Result obtained from serum biochemical analysis are expressed as Mean \pm SE and evaluated by student ' $t$ ' test. Urine biochemical results were collected from each group and statistically evaluated by Chi-square test for coming to conclusion. $\mathrm{p}$ value less than 0.05 was considered as significant. *p<0.05, $* * \mathrm{p}<0.01$.

\subsection{Effect of Asparagus racemosus Extract on Ash Con- tent of Femoral Bone in Ovariectomized Rats}

The effects of Asparagus racemosus Methanolic extract, Aqueous extract and Estrogen are summarized in Table 4. Ovariectomy did not produce any effect on total ash weight and percentage, but significantly reduced $(\mathrm{p}<0.01) 51.67 \pm$ 0.64 total calcium content in femoral bone ash. Treatment with estrogen appeared to increase ash weight $0.26 \pm 0.01$, ash percent $42.91 \pm 2.61$ and ash calcium $72.44 \pm 2.84$, but the changes did not reach statistical significance. Ovariectomy appeared to lower bone ash weight and percent, but treatment with either Methanolic extract or Aqueous extract prevented the ovariectomy induced decrease in ash weight and percent significantly. The effect Asparagus racemosus
Methanolic and Aqueous extract significantly increased $(p<0.01)$ total calcium content of ash when compared with ovariectomized rats groups.

\subsection{Effect of Asparagus racemosus Extract on Histopa- thological Changes in Ovariectomized Rats}

Histopathological observation of femur were shown epiphyseal region in ovariectomized rats were sparse, thinning of trabeculae with tendency of disappearance, loss of connectivity and widening of intertrabecular spaces as compared to normal and estrogen treated rats. Methanolic extract treated $(50 \mathrm{mg} / \mathrm{kg} \& 250 \mathrm{mg} / \mathrm{kg})$ rats had shown, lesser, moderately thick elongated trabeculae and narrowed intertrabecular spaces. In aqueous treated $(50 \mathrm{mg} / \mathrm{kg} \& 250$

Table 4. Effect of Asparagus racemosus Extract on Ash Content of Femoral Bone in Ovariectomized Rats

\begin{tabular}{|c|c|c|c|}
\hline Treatment & Ash Weight (g) & $\operatorname{Ash}(\%)$ & Calcium (mg) \\
\hline Normal Rats + DMSO & $0.23 \pm 0.01$ & $48.84 \pm 2.91$ & $70.08 \pm 3.82$ \\
\hline Ovariectomized Rats + Estrogen & $0.26 \pm 0.01$ & $42.91 \pm 2.61$ & $72.44 \pm 2.84$ \\
\hline Ovariectomized Rats + Aqueous Extract (50 mg/kg) & $0.24 \pm *$ & $48.64 \pm 2.25 *$ & $68.14 \pm 3.14 * *$ \\
\hline Overiectomized Rats + Methanolic Extract $(50 \mathrm{mg} / \mathrm{kg})$ & $0.29 \pm 0.01 * * *$ & $49.89 \pm 2.10 *$ & $67.40 \pm 2.98 * *$ \\
\hline Ovariectomized Rats + Methanolic Extract $(250 \mathrm{mg} / \mathrm{kg})$ & $0.26 \pm 0.01 *$ & $43.91 \pm 1.89$ & $64.39 \pm 2.65 * *$ \\
\hline
\end{tabular}

After bone mechanical parameters calculation by using left femur, it was used for estimating bone mineral content. Bone was incinerated in muffle furnace at $1000^{\circ} \mathrm{C}$ for 24 hour, total ash was weighed and percent ash was calculated from initial weight of femur. Calcium content of bone ash was analysed by using Span diagnostic kits. Result are expressed as Mean \pm SE and analysed by student ' $t$ ' test, for coming to conclusion. P value less than 0.05 was considered as significant. ${ }^{*} \mathrm{p}<0.05, * * \mathrm{p}<0.01$ and $\mathrm{p} * * *<0.01$ 
$\mathrm{mg} / \mathrm{kg}$ ) rats epiphyseal region of femur shown low thick trabeculae and wide and lost intertrabecular space as compare to Methanolic and estrogen treated rats.

Observation of reddish stained TRAP shown positive osteoclasts and increased in number of osteoclasts in ovariectomized rats as compare to normal and estrogen treated groups. The treatment of Methanolic extract $(50 \mathrm{mg} / \mathrm{kg}$ $\& 250 \mathrm{mg} / \mathrm{kg}$ ) rats were shown moderately decreased in number of osteoclasts, where as in aqueous extract of $A s$ paragus racemosus treated $(50 \mathrm{mg} / \mathrm{kg} \& 250 \mathrm{mg} / \mathrm{kg})$ rats highly increased in number of osteoclasts.

\section{DISCUSSION}

The current approach of designing anti-osteoporotic drug is directed with two basic processes of bone remodeling [18]. These agents are aimed either to prevent bone resorption (estrogen, calcitonin, bisphosphonates, calcium, vitamin D, and raloxifene) or to stimulate bone formation (fluoride, anabolic steroids) [28]. The most common type of osteoporosis is the bone loss associated with ovarian hormone deficiency at menopause. The mechanism by which ovary and hormone deficiency results in bone loss remains uncertain and several hypotheses have been linked to this condition. In human estrogen deficiency has been proposed to augment plasma calcium levels as a result of increased bone resorption [29]. The most frequently used anti-osteoporotic drugs are developed in affluent countries and the costs are too high to benefit the ordinary people in developing or even developed countries. Thus, alternative approaches for managing osteoporosis are needed [18]. Hence, this study was carried out, with an objective to evaluate anti-osteoporotic activity of Asparagus racemosus.

The most commonly used animal model for osteoporosis studies are the ovariectomized rats. The ovariectomized rat exhibits most of the characteristics of human postmenopausal osteoporosis [29]. In this study, the histopathology, biochemical markers and biomechanical results are similar to the earlier study in ovariectomized rats [13]. The effect on bone loss was studied by considering the ratio of bone loss to body weight to avoid the error due to variation in individual body weight throughout the study, along with decreased in the femoral length, weight, volume, and hardness in non treated ovariectomized rats. In this group the decreased bone mineral content was evidenced in reduction of total ash weight, ash percent and ash calcium content, ascertaining its role in the prevention of bone loss, similar to earlier reports [27]. Abnormal increase in loss of calcium and decrease in creatinine and phosphorous, in urine are supporting earlier studies on ovariectomized rats [18]. Similarly, increased in level of ALP was observed with respect to decreased in calcium and phosphorous in serum of ovariectomized animals. In our study, the increase in bone turnover and enhanced bone fragility, with disruptive and lytic changes in the bone architecture was observed in the histopathological study following ovariectomy, is indicative of the development of osteoporosis in rats due to estrogen deficiency and mimics human postmenopausal osteoporosis [12]. The absence of any significant change in calcium levels shows that homeostatic mechanisms maintain the serum calcium levels even after ovariectomy. Treatments with methanolic and aqueous extract of Asparagus racemosus for 40 days registered a sig- nificant increase in biomechanical strength, which was comparable to estrogen administered group. Histopathological examination of the femurs of extract treated groups 5 and 7 observed ossification, mineralization, calcified cartilaginous deposits and marginal osteoclastic activity, all of which indicate marked restorative action hereby, suggesting the protective action of the extract may be due to an increase in bone formation with reduction in bone resorption [30]. Higher dose of aqueous extract shows the significant decrease in alkaline phosphatase activity thus showing an enhancement of osteoblastic activity and reduction of osteoclastic activity.

The decrease in calcium absorption in the ovariectomized rat reports is similar to postmenopausal women [31]. Since, the decrease in serum ovarian hormone deficiency can decrease intestinal calcium absorption without altering vitamin D metabolism [32]. To some extent, we observed significant fall in serum calcium and phosphorous level may relates in part to lower serum albumin levels [26] despite, compensation metabolism and long half-life of steroid hormones. The methanolic effect of Asparagus racemosus significantly increased serum calcium levels, may be through increased intestinal absorption [33]. Fasting urinary calcium and phosphorous estimation are also considered as a useful tool for estimating net bone resorption. Treatment of ovariectomized rats with methanolic extract significantly decreased urinary calcium excretion suggesting more calcium deposition in bone [34]. In this study renal creatinine was also considered to find out the effect of Asparagus racemosus on renal performance. It has been observed that there was a significant decrease in renal creatinine clearance indicating possibility of nephrotoxicity, may be due to residual content of methanol.

The biomechanical parameters including, compression test of $4^{\text {th }}$ lumbar vertebra is one of the direct measures of bone strength [12]. In this study the $4^{\text {th }}$ lumbar vertebra hardness was decreased in ovariectomized rats and it was restored by treatment of aqueous and methanolic extracts. However, the results are not significant indicating need of the study for longer period then the period selected.

In adult rats, once longitudinal growth has essentially ceased than cancellous bone that undergoes remodeling. Ovariectomized was followed by increase in the bone turnover associated with bone loss and a permanent deficit of bone mass at several skeletal sites rich in trabecular bone, such as the vertebral bodies, the proximal femur, and the metaphyses of long bones such as the distal femur and proximal tibia [19]. There is also a transient increase in the endochondral growth, periosteal apposition and cancellous bone turn over with resorption exceeding formation [19]. In this study treatment with aqueous and methanolic extract of Asparagus racemosus significantly increased the length of left femur in ovariectomized rats, when compared to controls, indicating a small stimulatory effect of growth hormone on the longitudinal growth [17], through its effect on pituitary gland. This finding suggests that treatment with estrogen and methanolic extract of Asparagus racemosus could increase bone weight then compared to ovariectomized control rats, may have stimulatory effect on growth hormone and the deposition of calcium.

Asparagus racemosus W root used traditionally in ayurveda for various kinds of the disease and disorders and 
galactogogue [20] and nerve tonic [14]. The earlier phytochemical analysis have demonstrated the presence of an alkaloids, flavonoides, saponins, sterols, terpenes, phenols and sugars [21]. It has also been evaluated for antioxidant [22], anti-inflammatory [20], antimicrobial [23] antidiarroeal [19], and antiulcer [25] properties.

The preliminary phytochemical investigation of methanolic extract shown the presence of flavonoids and steroids (results are not given). Previous studies have shown that the natural flavones and steroids have been able in bone remodeling. After consumption of these phytosterone and isoflavone precursors, metabolic conversions occur in the gastrointestinal tract resulting in the formation of heterocyclic phenols that are similar in structure to estrogens. These phytoestrogens have a diphenolic ring in chemical structure that is very similar to endogenous estrogens, estradiol and diethylstilbestrol, accounting for their weak estrogen-like effect. These phytoestrogen found to bind two subtypes of estrogenic substance but more strongly to the $\beta$-estrogens. Therefore, they are considered as natural selective estrogen receptor modulators, as they appear to be estrogen agonists for cardiovascular system, bone and brain [24]. As steroidal estrogens are of benefit in preventing osteoporosis, phytoestrogens may have a protective effect in the postmenopausal women.

The use of this plant in the treatment of osteoporosis not only encounters orthopedics practice, but may also alleviated common symptoms such as backache, joint swelling, pain and stiffness as reported by earlier study [34-36]. The use of Asparagus racemosus is also appeared to be safe for longterm usage, as there were no short term and long term toxicity reports [20]. Based on these results, we conclude that the Asparagus racemosus methanolic extract is more potent in protecting the animals from osteoporosis than aqueous extract. All of their effects observed in this study are similar to estrogen treatment. Hence, Asparagus racemosus shall be considered as safe and effective antiosteoporosis in the treatment of postmenopausal condition.

\section{REFERENCES}

[1] Pande, K.C. Prevalence of low bone mass in healthy Indian population. J. Indian Med. Assoc., 2002, 100, 598-600.

[2] Handa, R. Management of osteoporosis, the Indian perspective. Clin. Calcium., 2004, 14, 100-105.

[3] Friedmann, P.A. Agents affecting mineral ion homeostasis and bone turn over; Laurence, L.B.; John, S.L.; Keith, L.P. Eds.; Goodman and Gilman's The Pharmacological Basis of Therapeutics, $11^{\text {th }}$ ed.; McGraw-Hill: New Delhi, 2006, pp. 1647-1678.

[4] Merck, H.B.; Robert, B. The Merck Manual of Diagnosis and Therapy. $7^{\text {th }}$ ed. Merck Research Laboratories: N.J., 2004, pp. 469473.

[5] Iqbal, M.M. Osteoporosis: epidemiology, diagnosis, and treatment. South Med. J., 2000, 93(1), 2-18.

[6] Ernesto, C. Novel treatment for osteoporosis. J. Clin. Invest., 2000, $106,177-179$.

[7] Lea, C.K.; Flanagan, A.M. Physiological plasma levels of androgens reduce bone loss in the ovariectomized rat. Am. J. Physiol., 1998, 274, E328-335.

[8] O' Connell, M.B.; Seaton, T.L. Osteoporosis and Osteomalacia; Joseph, J.D.; Robert, L.T.; Gary, C.Y.; Gary, R.M.; Barbara, G.M.; Michael, L.P. Eds.; Pharmacotherapy-A Pathophysiologic approach, $6^{\text {th }}$ ed.; McGraw-Hill: New Delhi, 1999, pp. 1645-1669.

[9] Arjmandi, B.H. The role of phytoestrogens in the prevention and treatment of osteoporosis in ovarian hormone deficiency. J. Am. Coll. Nutr., 2001, 20, 398S-402S.
[10] Joseph, C. Strontium ranelate promotes osteoblastic cell replication through at least two different mechanisms. Bone, 2008, 42(6), 1131-1136.

[11] Meng, F.H.; Li, Y.B.; Xiong, Z.L.; Jiang, Z.M.; Li, F.M. Osteoblastic proliferative activity of Epimedium brevicornum Maxim. Phytomedicine, 2005, 12, 189-193.

[12] Shirwaikar, A.; Khan, S.; Malini, S. Antiosteoporotic effect of ethanol extract of Cissus quadrangularis Linn. on ovariectomized rat. J. Ethnopharmacol., 2003, 89, 245-250.

[13] Nagareddy, P.R.; Lakshmana, M. Withania somnifera improves bone calcification in calcium-deficient ovariectomized rats. $J$. Pharm. Pharmacol., 2006, 58, 513-519.

[14] Nadkarni, A.K. Dr. K. M. Nadkarni's Indian Materia Medica. $3^{\text {rd }}$ ed.; Popular Prakashan Private Limited: Mumbai, 1976, pp. 153155.

[15] Guidelines, Division of Metabolic and Endocrine Drug Products (Maryland): Guidelines for preclinical and clinical evaluation of agents in the prevention or treatment of postmenopausal osteoporosis. FDA Rockville, 1994.

[16] Lasota, A.; Danowska-Klonowska, D. Experimental osteoporosisdifferent methods of ovariectomy in female white rats. Rocz Akad Med. Bialymst, 2004, 49, 129-131.

[17] Reddy, N.P.; Lakshmana, M.; Udupa, U.V. Antiosteoporotic activity of OST-6(Osteocare), a herbomineral preparation in calcium deficient ovariectomized rats. Phytother. Res., 2004, 18, 25-29.

[18] Xie, F.; Wu, C.F.; Lai, W.P.; Yang, X.J.; Cheung, P.Y.; Yao, X.S.; Leung, P.C.; Wong, M.S. The osteoprotective effect of Herba epimedii (HEP) extract in vivo and in vitro. Evid. Based Complement. Alternat. Med., 2005, 2, 353-61.

[19] Venkatesan, N.; Thiyagarajan, V.; Narayanan, S.; Arul, A.; Raja, S.; Vijaya kumar, S.G.; Rajarajan, T.; Perianayagam, J.B. Antidiarrhoeal potential of Asparagus racemosus W root extract in laboratory animals. J. Pharmacy Pharm. Sci., 2005, 8, 39-46.

[20] Mitra, S.K.; Venkataranganna, M.V.; Udupa, U.V.; Gopumadhavan, S.; Seshadri, S.J.; Rafiq, M.; Anturlikar, S.D.; Sundaram, R.; Tripathi, M. The beneficial effect of OST-6 (OsteoCare), a herbomineral formulation, in experimental osteoporosis. Phytomedicine, 2001, 8, 195-201.

[21] Goyal, R.K.; Singh, J.; Lal, H. Asparagus racemosus--an update. Indian J. Med. Sci., 2003, 57, 408-414.

[22] Ravikumar, P.R.; Soman, R.; Chetty, G.L.; Pandey, R.C.; Sukh dev. Chemistry of ayrvedic crude drugs: Part 6-(shatavari-1): Stucture of Shatavarin-4. Indian J. Chem., 1987, 26B, 1012-1017.

[23] Jayashree, P.K.; Krutin, K.B.; Thomas, P.A.; Devasagayam.; Venkatachalam, S.R. Antioxidant properties of Asparagus racemosus against damage induced by g- radiation in rat liver mitochondria. J. Ethnopharmacol., 2000, 71, 425-435.

[24] Rege, N.N.; Nazareth, H.M.; Isaac, A.A.; Karandikar, S.M.; Dahanukar, S.A. Immunotherapeutic modulation of intraperitoneal adhesions by Asparagus racemosus. J. Postgraduate Med., 1989, 35, 199-203.

[25] Sairam, K.; Priyambada, S.; Aryya, N.C.; Goel, R.K. Gastroduodenal ulcer protective activity of Asparagus racemosus: an experimental, biochemical and histological study. J. Ethnopharmacol., $86,1-10$.

[26] Kalu, D.N.; Liu, C.C.; Hardin, R.R.; Hollis, B.W. The aged rat model of ovarian hormone deficiency bone loss. Endocrinology, 1989, 124, 7-16.

[27] Prabhakara Reddy, N.; Lakshmana, M. Prevention of bone loss in calcium deficient ovariectomized rats by OST-6, a herbal preparation. J. Ethnopharmacol., 2003, 84, 259-264.

[28] Harada, S.I.; Rodan, G.A. Control of osteoblast function and regulation of bone mass. Nature, 2003, 423, 349-355.

[29] Heaney, R.P. A unified concept of osteoporosis. Am. J. Med., 1965, $39,877-880$.

[30] Turner, A.S. Animal models of osteoporosis--necessity and limitations. Eur. Cell, 2001, 22, 66-81.

[31] Arjmandi, B.H.; Alekel, L.; Hollis, B.W.; Amin, D.; StacewiczSapuntzakis, M.; Guo, P.; Kukreja, S.C. Dietary soybean protein prevents bone loss in an ovariectomized rat model of osteoporosis. J. Nutr., 1996, 126, 161-167.

[32] Gallagher, J.C.; Eisman, J.; Hamstra, A.; Arnaud, S.B.; DeLuca, H.F. Intestinal calcium absorption and serum vitamin D metabolites in normal subjects and osteoporotic patients: effect of age and dietary calcium. J. Clin. Invest., 1979, 64, 729-736. 
[33] Chan, S.D.H.; Chiu, D.K.H.; Atkins, D. Oophorectomy leads to a selective decrease in 1,25-dihydroxycholecalcifeal receptors in rat jejunal villous cells. Clin. Sci., 1984, 66, 745 .

[34] Ahmed, I.; Loknath Kumar, K.P.; Kumar, V. Efficacy of OST-6, polyherbal formulation in the management of osteoporosis in postmenopausal women. Orthop. Today, 2002, 4, 241-244.
[35] Shah, A.; Kolhapure, S.A. Evaluation of efficacy and safety of Reosto in senile osteoporosis: A randomized, double-blind placebocontrolled clinical trial. Indian J. Clin. Pract., 2004, 15, 25-36.

[36] Jha, N.K. Asparagus racemosus: Shatavari. Phytopharma, 2004, 5 , 3-9.

() Chitme et al.; Licensee Bentham Open.

This is an open access article licensed under the terms of the Creative Commons Attribution Non-Commercial License (http://creativecommons.org/licenses/by-nc/3.0/) which permits unrestricted, non-commercial use, distribution and reproduction in any medium, provided the work is properly cited. 